\title{
Treatment of Peripheral Ossifying Fibroma using Er,Cr:YSGG Laser: Report of Two Cases
}

\author{
Shipra Arora, Arundeep Kaur Lamba, Farrukh Faraz, Shruti Tandon, Kirti Chawla
}

\begin{abstract}
Peripheral ossifying fibroma (POF) is a non-neoplastic growth on the gingiva thought to arise from the periodontal ligament. Histopathologic analysis always reveals immature bone and osteoid within the lesion. Surgical excision is the treatment of choice. This report comprises of two cases of POFs which were removed using an Er,Cr:YSGG laser. Two patients of age 36 and 25 years reported with the growths which were causing constant irritation as well as esthetic problem. Lesions were removed using an Er,Cr:YSGG laser. The healing was uneventful and no suture or analgesic was required. The histopathological report confirmed them as POF. No relapse was observed till 1 year after surgery. Therefore with this laser, there is relatively bloodless and painless surgery and in postsurgical course there is minimal swelling and scarring so patient's compliance is much better with this laser as compared to other techniques and lasers.
\end{abstract}

Keywords: Peripheral ossifying fibroma, Er,Cr:YSGG laser, Benign tumors, Photomodulation.

How to cite this article: Arora S, Lamba AK, Faraz F, Tandon $S$, Chawla K. Treatment of Peripheral Ossifying Fibroma using Er,Cr:YSGG Laser: Report of Two Cases. Int J Laser Dent 2013;3(3):94-99.

\section{Source of support: Nil}

Conflict of interest: None declared

\section{INTRODUCTION}

Local reactive focal overgrowths are frequently found in the oral cavities. Different types of localized reactive lesions may occur on the gingiva, including focal fibrous hyperplasia, pyogenic granuloma, peripheral giant cell granuloma and peripheral ossifying fibroma (POF) ${ }^{1,2}$ POF is a solitary, non-neoplastic gingival growth which results from reactive response of periodontal ligament to local irritation such as trauma, microorganisms, plaque, calculus, restorations and dental appliances. ${ }^{3-5}$ Clinically, it is sessile or pedunculated with ulcerated and erythematous surface or exhibits a color similar to the surrounding gingiva. Most lesions are $<2 \mathrm{~cm}$ in size, although larger lesions occasionally occur. ${ }^{6}$ It can occur at any age range but the peak incidence is seen between the second and third decades. An occurrence in children reported has also been reported in literature. Though radiographic changes are not always evident with POF, occasionally foci of radiopaque material may be seen, particularly in larger lesions or lesions with overt mineralization. ${ }^{7,8}$ In children, POF causes alveolar erosion, displacement of teeth and delayed tooth eruption. ${ }^{9}$ Treatment of choice is conservative surgical excision of the lesion and periosteum at the base of the lesion with recurrence rates of 8 to $20 \%{ }^{9-11}$

Lesion can be excised using conventional scalpels, electrocautery, radiosurgery or lasers. Lasers have various advantages over conventional instruments for oral soft tissue excision. It results in a dry surgical field and better visualization, tissue surface sterilization, less postoperative pain and edema, scarring and faster healing response with increased patient acceptance. When used in noncontact mode it results in sharp incisions with minimum tissue distortion.

Different classes of lasers, such as $\mathrm{CO}_{2}, \mathrm{Nd}$ :YAG, diode, $\mathrm{He}-\mathrm{Ne}$ and excimer, have been evaluated for soft tissue excision and shown deleterious effects on tissues, such as carbonization, melting and denaturation of proteins with consequent formation of toxic substances as well as compositional changes on the irradiated tissues.

A new addition to laser group is Er,Cr:YSGG of erbium family. The water absorption coefficient of this group is higher than other laser groups so laser energy is absorbed by water molecules which causes quick heating, vaporization, and microexplosions which results in ablation with minimal heating and in the absence of carbonization. ${ }^{12,13}$

Thus, the aim of this paper is to evaluate the treatment outcome of two cases of POF which were treated using Er,Cr:YSGG laser.

\section{CASE REPORTS}

\section{Case 1}

A 36-year-old female patient reported to the Outpatient Department of Periodontics on November 2012 with a chief complaint of swelling on the lower front teeth since 2 years which was causing constant irritation (Fig.1). History reveals that initially the growth was of pea size and had gradually grown to the present size $(3 \times 2 \mathrm{~cm})$ since then (Fig. 2). The patient complains that the lump was interfering with movement of tongue and was not causing any pain. Patient had not seen any physician or dentist since then. The patient was in good health and had no other significant medical and family history.

Clinical examination of the lump revealed an exophytic pinkish sessile mass with smooth surface in the oral cavity lingual to the mandibular central incisors (Fig. 1). Lesion revealed a solitary, well defined, firm, nontender, nonfluctuant, nonpulsatile mass with the size $3 \times 2 \mathrm{~cm}$ 


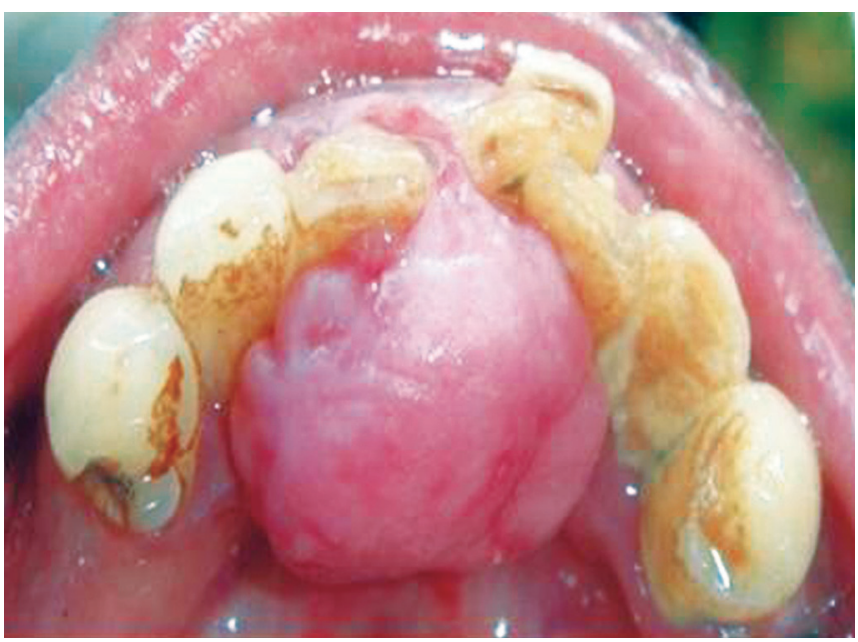

Fig. 1: Preoperative lingual view of case 1 before phase 1 therapy of case 1

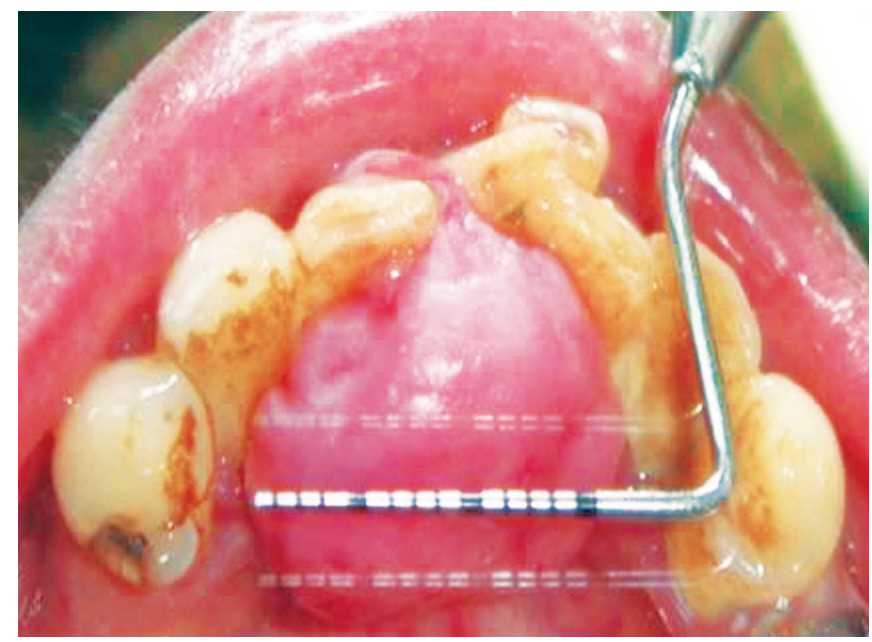

Fig. 2: Preoperative mesiodistal measurement of case 1 before phase 1 therapy of case 1

(Fig. 2). Supragingival and subgingival calculus deposits were present. Lesion was interfering in oral hygiene measures, speech and masticatory functions.

A provisional diagnosis of fibroma was made. The differential diagnosis included peripheral giant cell granuloma, pyogenic granuloma and ossifying fibroma.

\section{Case 2}

A 25-year-old female reported with the chief complaint of a growth on the maxillary labial gingiva of right side since 4 months (Fig. 3). Growth was slightly painful and unesthetic in appearance. No significant medical history or family history was present.

On clinical examination, reddish sessile growth of $8 \times$ $6 \mathrm{~mm}$ size with smooth surface was found at the labial gingiva in the interdental region with respect to 25 and 26. Growth was irregular in shape and was firm and nonfluctuant in consistency with mild tenderness on palpation. There was no calculus or caries present on the adjacent teeth.

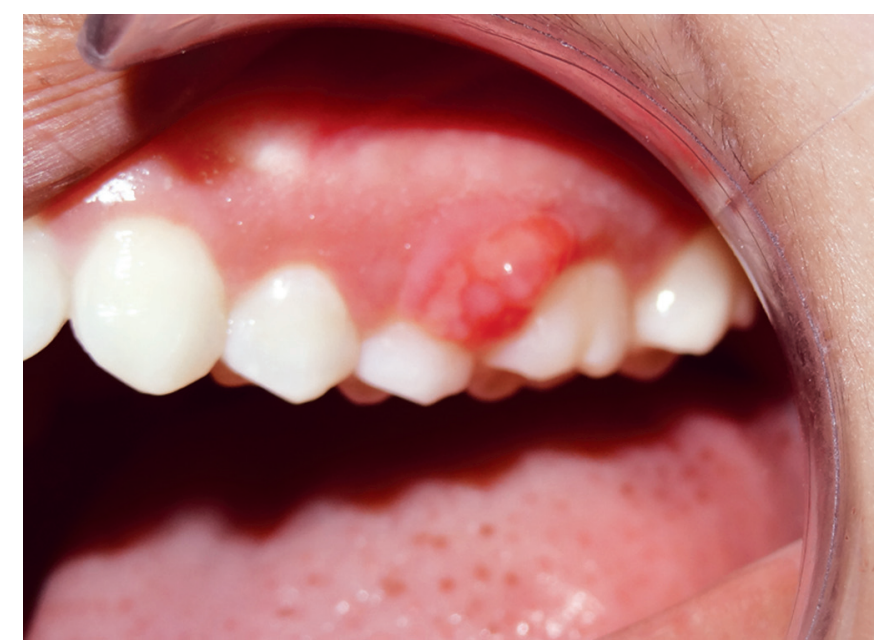

Fig. 3: Preoperative buccal view of case 2 after phase 1 therapy of case 2

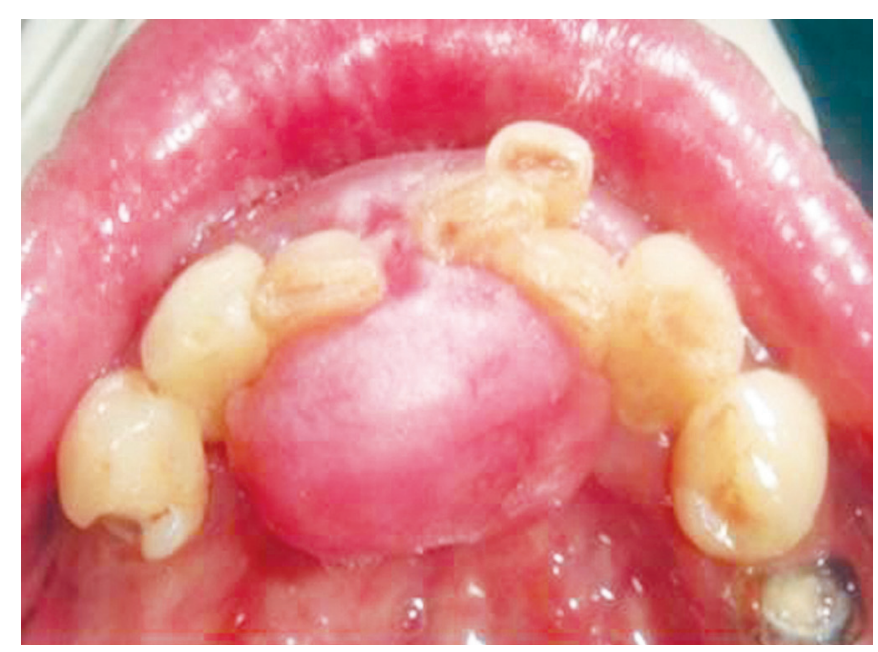

Fig. 4: Preoperative lingual view after phase 1 therapy of case 1

\section{Management}

Both the cases were treated using Er,Cr:YSGG laser.

Phase I therapy was done before the laser treatment (Fig. 4).

Excisional biopsies were performed under local anesthesia to remove the lesion using Er,Cr:YSGG laser (Waterlase YSGG, C 100, Biolase technology) (Figs 5 and 6). Topical anesthetic gel comprising of $2 \%$ lignocaine hydrochloride gel (xylocaine 2\% gel, AstraZeneca, London, UK) was applied prior to laser treatment. Patient and staff used special eye glasses for protection. The lesions were stabilized with Tweezer. The borders of the lesions were outlined. The Er,Cr:YSGG application (short pulse ' $\mathrm{H}$ ' mode) was done with zirconium (Z6) tip of $6 \mathrm{~mm}$ in length and $6 \mu \mathrm{m}$ in diameter, $1.5 \mathrm{~W}$ power, $13 \%$ air and $9 \%$ water in noncontact mode (Figs 7 and 8). Care was taken to prevent darkening of the tissue, which is indicative of aggressive ablation. Upon complete excision of the lesion, a laser bandage to control hemorrhage was applied by tracing 
the edges of the incision as well as lightly 'painting' the surface of the tissue bed with a setting of 0.5 Watt with no air and water (Figs 9 and 10). No sutures were given. The specimens were sent to the laboratory for histopathological examination.

On histopathological examination stained with hematoxylin and eosin (H\&E), stratified squamous epithelium with elongated rete ridges was seen. Irregular multiple foci of homogeneous calcified areas were evident within the connective tissue. Most of the nodule consisted of hypercellular, well-vascularized fibrous connective tissue (Figs 11 and 12).

The patients were seen at 1 week follow-up (Figs 13). No scar tissue and no postoperative pain were observed. Healing was satisfactory. The area of excisions was not tender on palpation and the affected areas displayed complete healing. Patients were followed up for 1 year and no recurrence was seen.

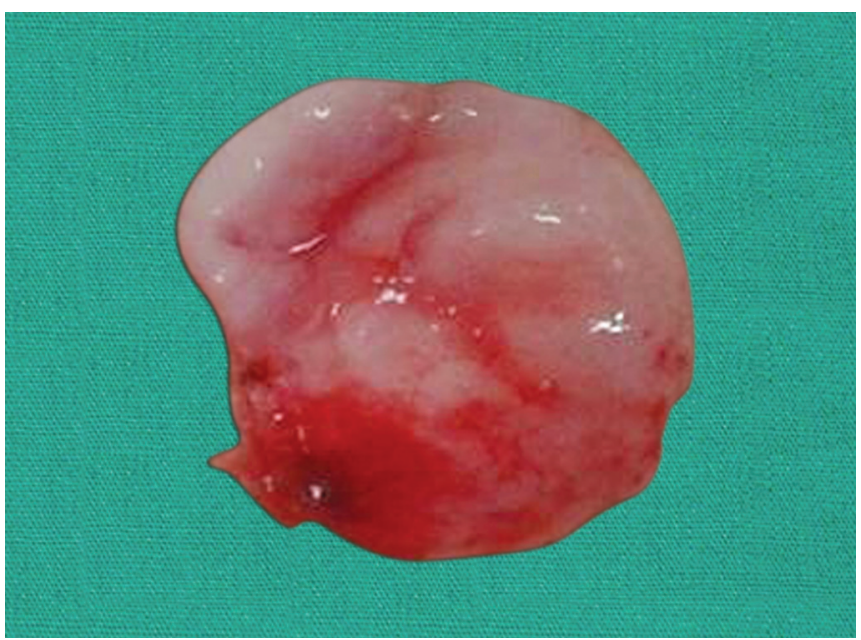

Fig. 5: Excised tissue of case 1

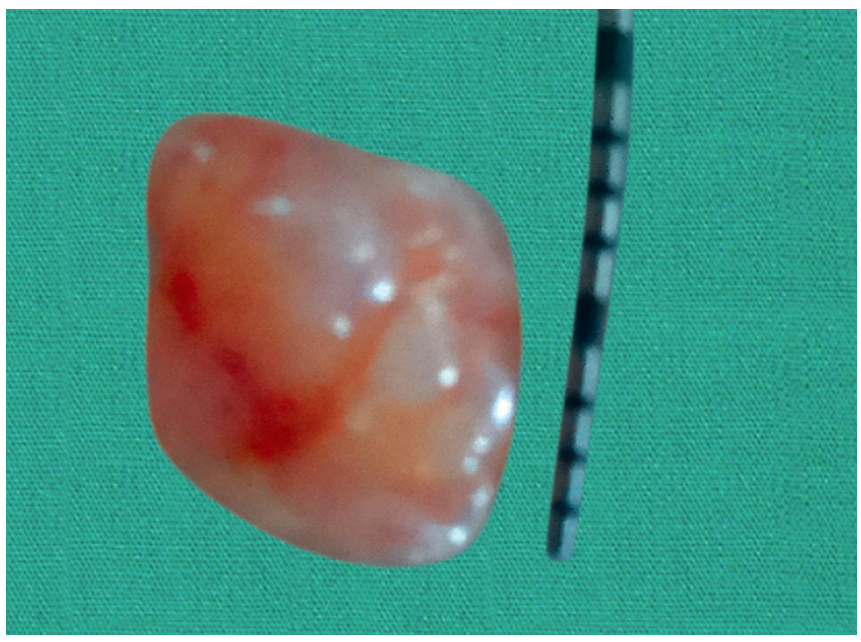

Fig. 6: Excised tissue of case 2

\section{DISCUSSION}

POF has been given many synonyms, such as epulis, calcifying fibroblastic granuloma, peripheral cementifying fibroma, peripheral fibroma with cementogenesis, peripheral cemento-ossifying fibroma, ossifying fibroepithelial polyp and peripheral fibroma with osteogenesis. ${ }^{14}$

Bhasker in 1984 described this lesion as peripheral fibroma with calcification and Eversol and Robin coined the term POF. ${ }^{15,16}$ The etiopathogenesis of POF remain unclear. It can be a result of tissue response to trauma or local irritants such as subgingival plaque and calculus, dental appliances, poor-quality dental restorations, microorganism or masticatory forces. ${ }^{15}$

Various terms can be used to describe lesion depending on the nature of calcific tissue present. If bone predominates ossifying is the appellation, if cementum predominates the term cementifying is used. ${ }^{3}$ If bone and cementum like

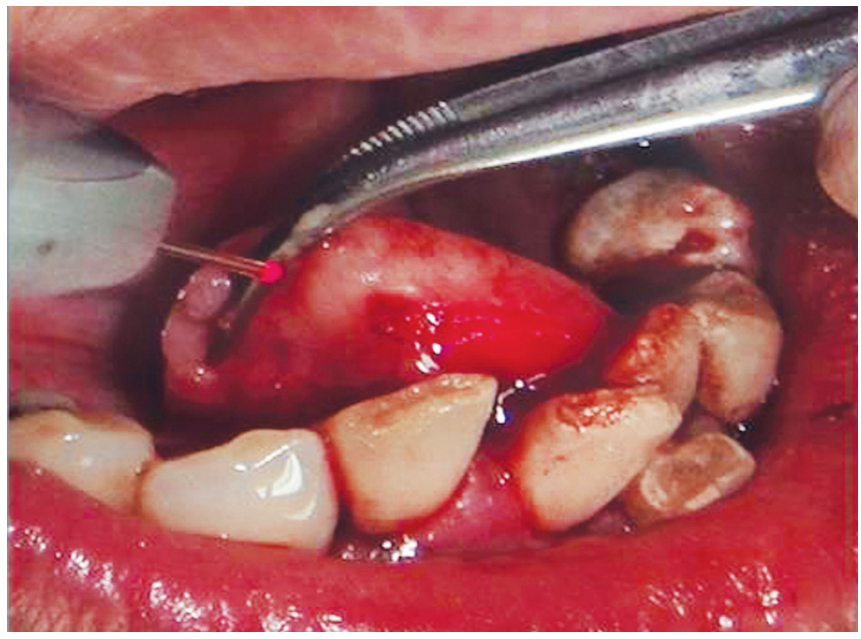

Fig. 7: Intraoperative view with Er,Cr:YSGG laser irradiation of case 1

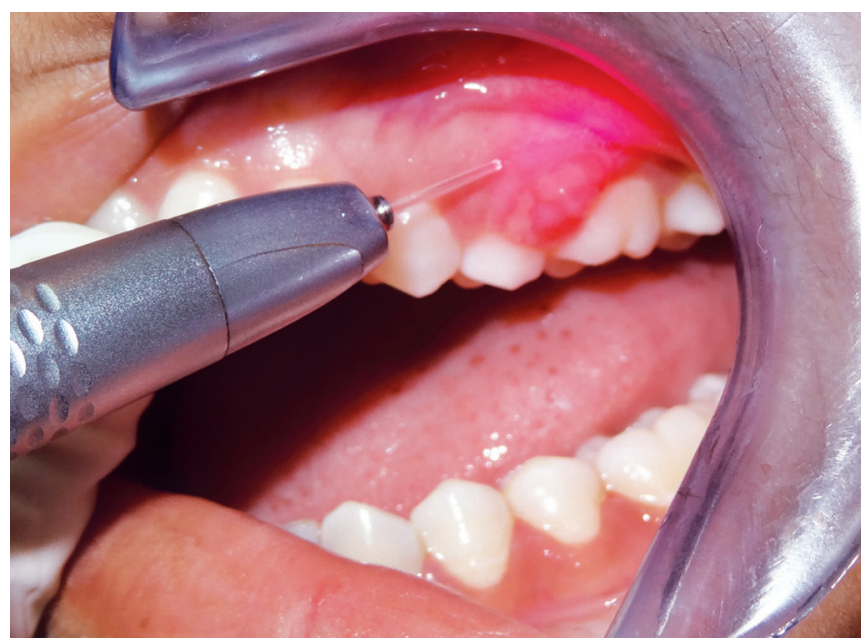

Fig. 8: Intraoperative view with Er,Cr:YSGG laser irradiation of case 2 


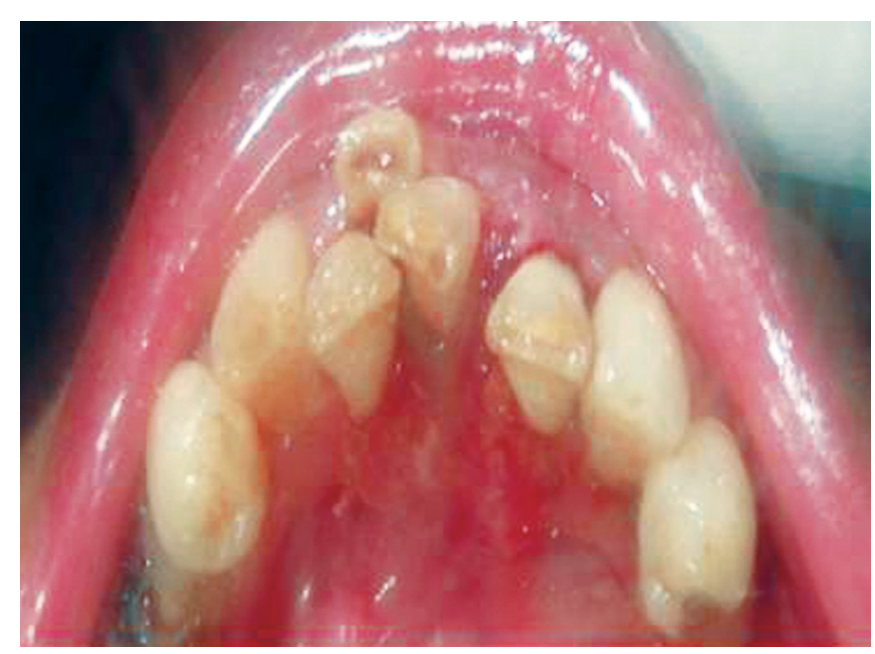

Fig. 9: Immediate postoperative view of case 1

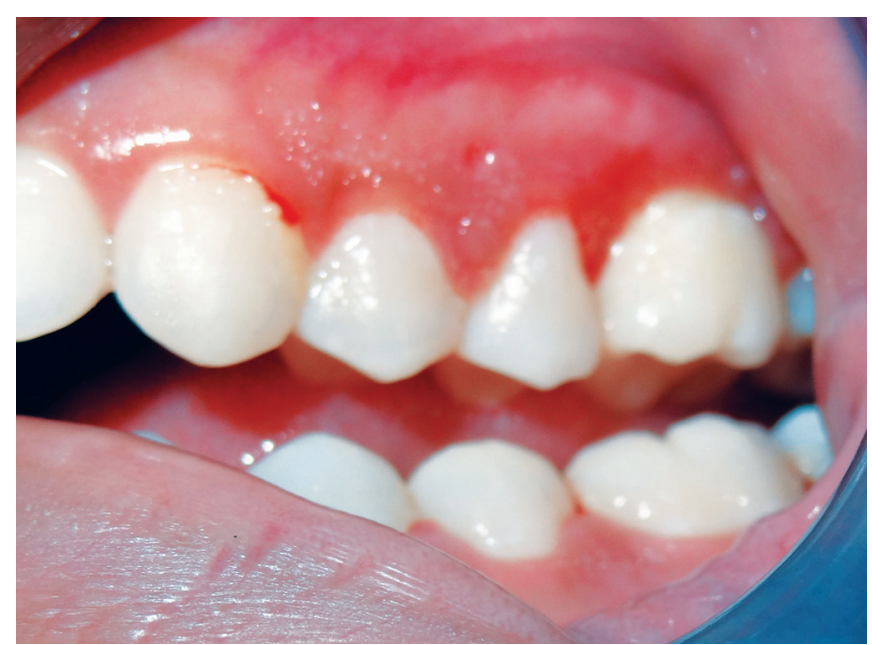

Fig. 10: Immediate postoperative of case 2

tissues are observed, the lesions have been referred to as cemento-ossifying fibroma. Ossifying fibromas usually elaborate calcified tissues such as bone, cementum and spheroidal calcifications, which has given rise to different nomenclature for these benign fibro-osseous neoplasms. If bone predominates ossifying is the appellation, if cementum predominates the term cementifying is used. If bone and cementum like tissues are observed, the lesions have been referred to as cemento-ossifying fibroma. There is high female predilection and a peak occurrence is in the secondthird decade of life. ${ }^{9}$

On radiographic examination, radiopaque foci of calcification were seen in the central area. Underlying bone involvement is usually not visible. In rare instances, superficial erosion of bone is noted. ${ }^{17}$

A confirmatory diagnosis of POF is made by histopathological examination. Microscopically, the features of POF consist of (1) intact or ulcerated stratified squamous surface epithelium; (2) fibrous connective tissue with varying

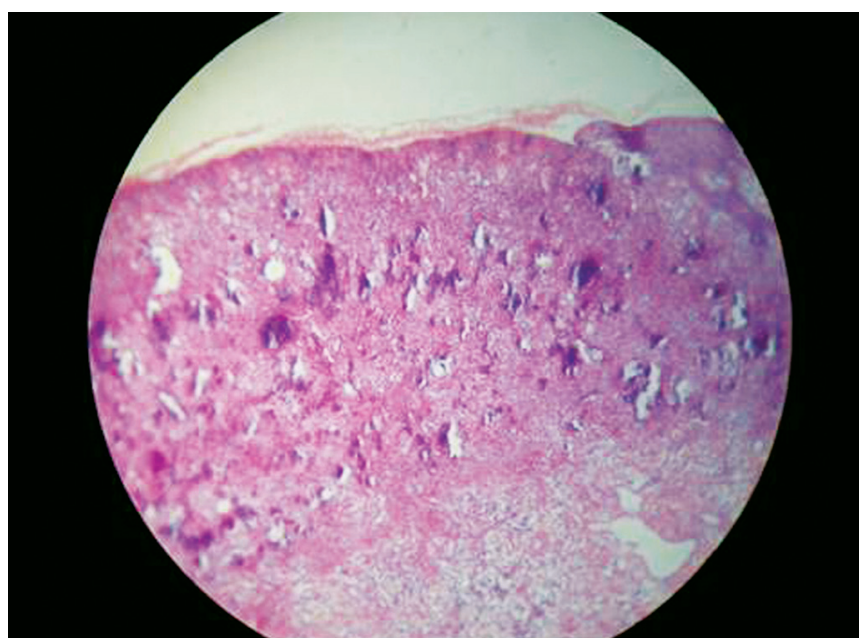

Fig. 11: Histopathology view at $40 \times$ of case 1

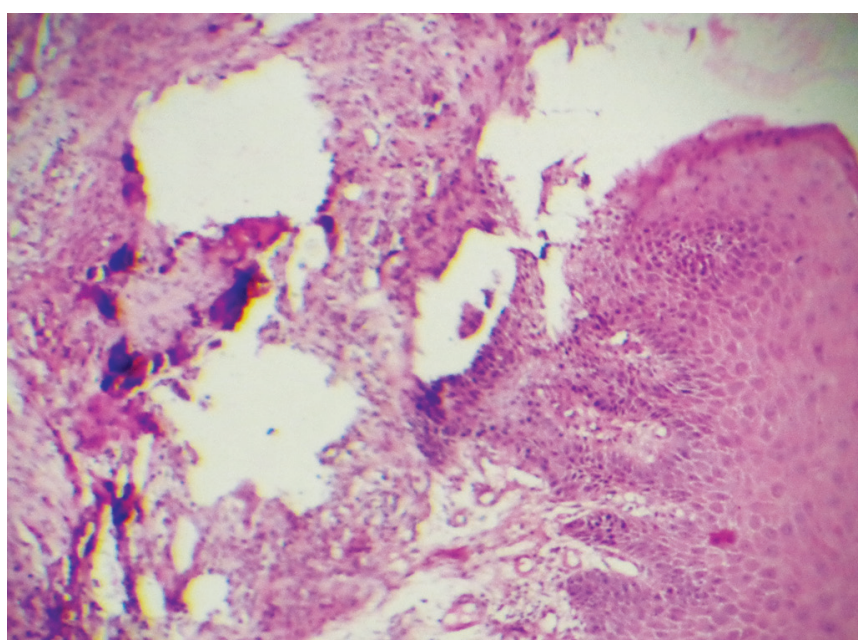

Fig. 12: Histopathology view at $40 x$ of case 2

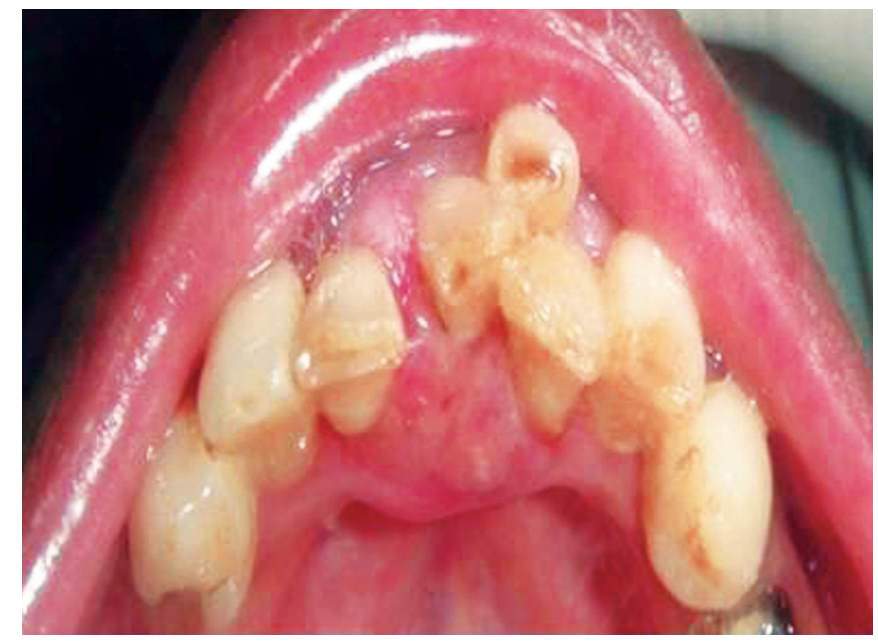

Fig. 13: Postoperative 1 week of case 1

numbers of fibroblasts; (3) sparse to profuse endothelial proliferation; (4) mineralized material consisting of mature, lamellar or woven osteoid, cementum like material, or dystrophic calcifications; (5) chronic inflammatory cells in the lesion. ${ }^{4,17}$ Above features are seen in this case. 
Treatment of POF consists of elimination of etiological factors, scaling of adjacent teeth and total aggressive surgical excision along with involved periodontal ligament and periosteum to minimize the possibility of recurrence. ${ }^{18}$ The lasers have a number of advantages over the scalpel or electrosurgery. Incisions are sharp, self-sterilizing and with reduced postoperative scarring. ${ }^{19}$ Lasers causes a relatively bloodless surgical and postsurgical course, minimal swelling and scarring, coagulation and cutting minimal or no suturing, reduction in surgical time when infiltrated anesthesia is used and in a majority of cases much less or no postsurgical pain. ${ }^{20}$ In the present case, we have used Er,Cr:YSGG laser. The safety and efficacy of laser systems is already evaluated for the treatment of facial pigmentation and vascular lesions and in oral surgery for example upper and lower frenectomy, fibroma and excision of epulis fissuratum and gingival hyperplasia. ${ }^{21} \mathrm{Er}, \mathrm{Cr}$ :YSGG laser of the erbium family have higher water absorption coefficient which causes rapid vaporization and microexplosions that creates high pressure on the surrounding cells. ${ }^{13}$

Advantage of using Er,Cr:YSGG laser (medium infrared: $2,780 \mathrm{~nm})$ over the near infrared laser $(810 \mathrm{~nm}$ to 1,064$)$ is that it cause less thermal deep or lateral damage as the heat escapes by means of vaporization. Good hemostatic control was achieved by photothermal induced coagulation. When used in noncontact technique, it causes minimal tissue distortion. Also erbium family lasers can generate reactive oxygen species in irradiated tissue which have sterilization effects that stimulate fibroblasts, collagen, and extracellular matrix formation. ${ }^{22-24}$ This laser causes minimum carbonization, which promote tissue repair by phenomenon known as photomodulation. ${ }^{14}$ It works at cellular levels in toxin reduction, accelerating lymphatic flow and increasing blood flow thereby supporting pain reduction. It also enhances repair and induces regeneration by means of expression of collagen and elastic fibers during the early phase of wound healing.

\section{CONCLUSION}

The laser technique used in this study was an effective choice. The therapeutic success was due to the good intraoperative cooperation of the patient, good hemostatic control postoperative wound healing. There is no scaring and relapse on 1 year follow-up.

\section{CLINICAL SIGNIFICANCE}

With the use of this water laser there is relatively bloodless, painless surgery and in postsurgical course there is minimal swelling and scarring so patient compliance is much better with this laser as compare to other techniques and lasers.

\section{REFERENCES}

1. Narty N, Masadomi H, Al-Gilani M, Al-Mobeerik A. Localized inflammatory hyperplasia of the oral cavity: clinico-pathological study of 164 cases. Saudi Dent J 1994;6:145-150.

2. Bouquot J. Common oral lesions found during a mass screening examination. J Am Dent Assoc 1986;112:50-72.

3. Eversole LR, Rovin S. Reactive lesions of the gingival. J Oral Pathol 1972;1:30-38.

4. Kumar SK, Ram S, Jorgensen MG, Shuler CF, Sedghizadeh PP. Multicentric peripheral ossifying fibroma. J Oral Sci 2006;48:239-243.

5. Neville BW, Damm DD, Allen CM, Bouquot JE. Oral and maxillofacial pathology. Philadelphia: Saunders. 1995. p. 451-452.

6. Das UM, Azher U. Peripheral ossifying fibroma. J Indian Soc Pedod Prev Dent 2009;27:49-51

7. Flaitz CM. Peripheral ossifying fibroma of the maxillary gingival. Am J Dent 2001;14:56.

8. Gardner DG. The peripheral odontogenic fibroma: an attempt at classification. Oral Surg Oral Med Oral Pathol 1982;54:40-48.

9. Kenney JN, Kangars GE, Abbey LM. Comparison between the peripheral ossifying fibroma and peripheral odontogenic fibroma. J Oral Maxillofac Surg 1989;47:378-382.

10. Bhaskar SN, Jacoway JR. Peripheral fibroma and peripheral fibroma with calcification: report of 376 cases. J Am Dent Assoc 1966;73:1312-1320.

11. Cuisia ZE, Brannon RB. Peripheral ossifying fibroma: a clinical evaluation of 134 perdiatric cases. Pediatr Dent 2001;23:245-248.

12. Nobor T, Miyazaki Y, Moriyama I, Sannikorn P, Ohyama M. Contact Nd-YAG laser technique applied to heal to head and neck reconstructive surgery. J Laser Surg 1989;1066:177-179.

13. Tal H, Oegiesser D, Tal M. Gingival depigmentation by erbium:YAG laser: clinical observations and patient responses. J Periodontol 2003;74:1660-1667.

14. Riggs K, Keller M, Humphreys TR. Ablative laser resurfacing: high-energy pulsed carbon dioxide and erbium:yttriumaluminum-garnet. Clin Dermatol 2007;25:462-473.

15. Farquhar T, MacLellan J, Dyment H. Peripheral ossifying fibroma: a case report. J Can Dent Assoc 2008;74:809-812.

16. Mesquita RA, Orsini SC, Sousa M, de Araújo NS. Proliferative activity in peripheral ossifying fibroma and ossifying fibroma. J Oral Pathol Med 1998;27:64-67.

17. Keluskar V, Byakodi R, Shah N. Peripheral ossifying fibroma. Journal of Indian Academy of Oral Medicine and Radiology 2008;20:54-56.

18. Kendrick F, Waggoner WF. Managing a peripheral ossifying fibroma. J Dent Child 1996;63:135-138.

19. Prasad S, Reddy SB, Patil SR, Kalburgi NB, Puranik RS. Peripheral ossifying fibroma and pyogenic granuloma are they interrelated? N Y State Dent J 2008;74(2):50-52.

20. Pick RM, Colvard DM. Current status of lasers in soft tissue dental surgery. J Periodontol 1993;64:589-602.

21. Desiate A, Cantore S, Tullo D, Profeta G, Grassi FB, Ballini A. $980 \mathrm{~nm}$ diode lasers in oral and facial practice: current state of the science and art. Int J Med Sci 2009;6:358-364.

22. Olivi G, Costacurta M, Maturo P, Docimo R. Removal of fibrous epulis with Er,Cr:YSGG: a case report. Eur J Paediatr Dent 2007 Sep;8(3):149-152.

23. Ishikawa I, Aoki A, Takasaki AA. Potential applications of erbium:YAG laser in periodontics. J Periodontal Res 2004;39: 275-285.

24. Azzeh MM. Treatment of gingival hyperpigmentation by erbiumdoped:yttrium, aluminum, and garnet laser for esthetic purposes. J Periodontol 2007;78:177-184. 


\section{ABOUT THE AUTHORS}

\section{Shipra Arora (Corresponding Author)}

Postgraduate Student, Department of Periodontics, Maulana Azad Institute of Dental Sciences, New Delhi, India, Phone: 9958168906 e-mail: dr.shipraarora09@gmail.com

\section{Arundeep Kaur Lamba}

Professor and Head, Department of Periodontics, Maulana Azad Institute of Dental Sciences, New Delhi, India

\section{Farrukh Faraz}

Associate Professor, Department of Periodontics, Maulana Azad Institute of Dental Sciences, New Delhi, India

\section{Shruti Tandon}

Associate Professor, Department of Periodontics, Maulana Azad Institute of Dental Sciences, New Delhi, India

\section{Kirti Chawla}

Senior Resident, Department of Periodontics, Maulana Azad Institute of Dental Sciences, New Delhi, India 